\section{Story of a synthetic polypeptide}

\section{Jen Tsi Yang}

Poly ( $\gamma$-Benzyl-L-Glutamate) and Other Glutamic Acid Containing Polymers. By H. Block.

Gordon \& Breach: 1984. Pp.215. \$49.

Poly( $\gamma$-benzyl-L-glutamate) is unique, the first synthetic polypeptide studied that is a helical rod in helicogenic solvents and a "random coil" in "good" solvents. In the 1950 s several laboratories in Britain, the United States and Israel were especially active in investigating this polypeptide. They were heady times. One morning in 1954, I remember, I was with Professor P. Doty at Harvard when a co-worker of his rushed in with a new set of data. Doty paused and plotted them on a graph; the data fitted nicely on a viscosity-molecular weight plot for rigid rods with the dimensions of $\alpha$-helices - an exciting moment in an exciting era of biophysical chemistry.

Work was soon extended to poly $(\mathrm{L}$ glutamic acid), prepared by removing the protective benzyl group. Since then aspects of the helix-coil transition, both experimental and theoretical, have fascinated many researchers and Professor Block's book covers much of the story to date. However, the water-soluble poly(Lglutamic acid), which is equally versatile in its conformations as poly $(\gamma$-benzyl-Lglutamate) and is related to protein conformation, is hardly noted.

Two-fifths of the text is devoted to solution properties (Chapter 5) and about one-third to the solid state and surface properties (Chapter 6), these chapters following a brief introduction and accounts of syntheses and reactions. A short chapter on commercial exploitation completes the book, but it is poly $(\gamma$-methylL-glutamate) rather than poly $(\gamma$-benzyl-L glutamate) - the cost of which remains an obstacle - that has found use in making fibres, films and leather substitutes. One attractive feature is the bibliography which contains over 900 references. Many of these are now classics, and newcomers to the field will be able to use this part of the book to dig out useful background reading.

Professor Block surveys various topics from organic syntheses to physical studies, but in such a short volume the coverage of each is bound to be somewhat sketchy. Recent developments in the synthesis of sequential polypeptides are listed, for instance, but the brief discussion fails to do them justice. Readers will also need to be familiar with the various techniques to follow the text in detail. Often the terminology is not as well defined as it might have been; for example the narrow Poisson distribution for polydispersity of the amine-initiated polymer formation is not only poorly defined but the probable causes for departures from it are not considered. The kinetic treatment of copolymerizations is also somewhat scant, and while the formal results of the ZimmBragg theory for the helix-coil transition are presented, a simple heuristic quasichemical treatment would have made the whole phenomenon more comprehensible. Happily, the subsequent calorimetric studies of this process are taken up in more detail.

The book contains only nine figures, surely too few for this is in part a visual subject. In particular I would like to have seen a Zimm plot for light-scattering data - the classical method of determining the size and shape of the polypeptide as helical rods in helicogenic solvents.

I must also say that I find questionable

\section{Becoming a mammal}

\section{Gillian King}

The Evolution of Mammalian

Characters.

By D.M. Kermack and

K.A. Kermack. Croom Helm:

1984. Pp.149. f15.95.

THE mammal-like reptiles, or synapsids, have not had the exposure (popular or academic) with which their bigger and brasher relatives, the dinosaurs, have been favoured. When, for instance, did we last see a voluptuous film-star in fur bikini being chased by Inostrancevia? Even the names are not very familiar.

Yet the synapsids have left an excellent fossil record and present us with mysteries every bit as stimulating as those of the archosaurs: warm-bloodedness, extinction, descendants, transitions. Yet still no public recognition, until the past few years, when a few books, at least, have been published. Most recent in that short line is The Evolution of Mammalian Characters, which sets out to give an account of the origin and evolution of certain of the characters of the Mammalia, and to portray the fossils described as the living animals they once were.

The book begins with sections on vertebrate evolution from the earliest vertebrates to the cynodonts, as a brief introduction and background to the main subject. While I sympathize with the authors not wanting, for example, to get bogged down in the Devonian swamp of tetrapod origins, I found this whistle-stop survey sometimes frustratingly misleading or surprisingly archaic. For example, no mention is made of the fact that some workers propose that tetrapods might not have arisen from the crossopterygian fish, while dinocephalians are now generally considered to represent a monophyletic group. The style of writing is also somewhat dogmatic or old-fashioned in places: the basic rationale of this series of monographs, which "excludes macromolecules of purely academic interest". Before the development of recombinant DNA techniques, and the ensuing rise of a biotechnology industry, such biopolymers as polynucleotides, let alone restriction endonucleases, would have been judged as "useless"'. That is to say, today's laboratory curiosity may be the gleam in the eye of tomorrow's venture capitalists. One can hope that the fascinating story of poly $(\gamma$ benzyl-L-glutamate) and poly(L-glutamic acid) will nonetheless simulate further applied research and that Professor Block's book will help towards that end. $\square$

Jen Tsi Yang is Professor of Biochemistry at the University of California, San Francisco.

"Evolution is slow, continuous and imperceptible. The evolution of major taxa does not differ in any fundamental way from the evolution of one sub-species from another''(p.49).

But the real aim of the book is to describe the origin of certain mammalian characters. Chapter 5 attempts this for dentition. At first sight this is a clear and interesting account, a potentially helpful introduction for undergraduates. Closer reading, however, reveals that there is no real attempt to address the mechanical issues involved, or the influence of muscles in the story, and the result is rather unsatisfying.

The references, too, are disappointing, especially in view of the authors' attempts to cover the literature of the past ten years. There are some surprising gaps - no reference to Bramble (1978) on jaw mechanics; hardly any to Kielan-Jaworowska's work post-1971; and no specific references to any of Kemp's papers. By contrast the illustrations are very good. Not only are many of the fossils themselves illustrated, but two particularly valuable diagrams for teaching - of standard dental terminology and cusp nomenclature - are included as well as some useful time distribution charts.

The authors say that this is a personal book, which must deflect criticism to some extent, but to me it seems that they have fallen between two stools. The book is not as comprehensive or readable as the standard undergraduate texts incorporating the mammal-like reptiles, yet it contains too many ex cathedra opinions to qualify as a formal review. Nevertheless, there are interesting chapters on the evolution of mammalian senses and summaries of Middle Jurassic to Upper Cretaceous mammalian faunas which students and research workers may find useful.

Gillian King is Fellow in Zoology at St Hilda's College, University of Oxford, and Assistant Curator at the University Museum. 